\title{
Barriers and determinants of postpartum family planning uptake among postpartum women in Western Ethiopia: a facility-based cross-sectional study
}

Temesgen Tilahun ${ }^{1 *}$ (D) Tariku Tesfaye Bekuma², Motuma Getachew², Rut Oljira ${ }^{2}$ and Assefa Seme ${ }^{3}$

\begin{abstract}
Background: Despite Ethiopia's efforts to avail postpartum family planning (PPFP) services, the unmet need for family planning among postpartum women remains high. Therefore, this study is aimed to assess barriers and determinants of postpartum family-planning uptake among women visiting Maternal, Neonatal, and Child Health (MNCH) services in public health facilities of western Ethiopia.

Methods: A facility-based cross-sectional study design with a quantitative method was conducted on 989 postpartum women in Western Ethiopia from September 1 to October 30, 2020. Data were collected through faceto-face interviews using pretested structured questionnaires, entered using EPI-INFO version 7.0, and analyzed by SPSS version 25. Descriptive analysis and logistic regressions were performed. The adjusted odds ratio with a $95 \%$ confidence interval was used and statistical significance was declared at $P$-value $<0.05$.

Result: In this study, $56.1 \%$ of participants had used PPFP in the last year. The most commonly used method was injectable (51.7\%). Family planning use before the index pregnancy (AOR $=2.09 ; 95 \% \mathrm{Cl}: 1.29,3,41)$, counselling on PPFP during antenatal care and delivery $(\mathrm{AOR}=4.89 ; 95 \% \mathrm{Cl}: 2.31,10.37)$, health facility delivery ( $\mathrm{AOR}=7.61 ; 95 \% \mathrm{Cl}: 4.36,13.28)$, skilled birth attendance ( $A O R=4.99 ; 95 \% \mathrm{Cl}: 2.88,8.64), \mathrm{COVID}-19$ restrictions $(\mathrm{AOR}=0.59 ; 95 \% \mathrm{Cl}: 0.39,0.90)$ were factors associated with PPFP utilization. Being breastfeeding and amenorrhea were major reasons for not using postpartum family planning.

Conclusion: Post-partum family planning utilization among study participants was low. Given the associated factors, it is recommended that health facilities should make postpartum family planning one of their top priorities and focus on these factors to improve its utilization.
\end{abstract}

Keywords: Post-partum, Family planning, Barriers, Western Ethiopia

* Correspondence: ttamuko@yahoo.com

${ }^{1}$ Department of Obstetrics \& Gynecology, School of medicine, Institute of Health Sciences, Wollega University, Nekemte, Ethiopia

Full list of author information is available at the end of the article

(c) The Author(s). 2022 Open Access This article is licensed under a Creative Commons Attribution 4.0 International License, which permits use, sharing, adaptation, distribution and reproduction in any medium or format, as long as you give appropriate credit to the original author(s) and the source, provide a link to the Creative Commons licence, and indicate if changes were made. The images or other third party material in this article are included in the article's Creative Commons licence, unless indicated otherwise in a credit line to the material. If material is not included in the article's Creative Commons licence and your intended use is not permitted by statutory regulation or exceeds the permitted use, you will need to obtain permission directly from the copyright holder. To view a copy of this licence, visit http://creativecommons.org/licenses/by/4.0/ The Creative Commons Public Domain Dedication waiver (http://creativecommons.org/publicdomain/zero/1.0/) applies to the data made available in this article, unless otherwise stated in a credit line to the data. 


\section{Background}

The postpartum period is a critical time to address the high unmet need of family planning and to reduce the risks of closely spaced pregnancies [1]. Contraception is particularly important during the postpartum period to deter terrible maternal, neonatal, and child morbidity and mortality. Since 2010, the World Health Organization (WHO) has been receiving an increasing number of requests from country programs for strategies to create or strengthen voluntary family planning programs for women in the first year after childbirth [2]. As many as $50-90 \%$ of women from 17 low- and middleincome countries (LMICs) report an unmet need for postpartum family planning (PPFP) [2]. Women frequently return to fertility before initiating contraception after delivery and do not necessarily understand the risk of pregnancy before the return of menses [3]. WHO recommends PPFP as a critical component of health care that has the potential to meet women's desire for contraception and save millions of maternal and infant lives in low- and middle-income countries [4].

The uptake of postpartum family planning in subSaharan Africa remains low, especially with the lowest use observed in East Africa which varied from 10.3\% in Ethiopia to $73.7 \%$ in Uganda [5]. Perceptions of low pregnancy risk due to breastfeeding and postpartum amenorrhea, fear of method-related side effects, and poor family planning counseling were factors associated with the low uptake of PPFP while women who received good PPFP counseling during antenatal and postnatal care were more likely to use PPFP $[4,5]$.

The Ethiopian Health Sector Development Program (HSDP) IV sets a goal of improving maternal health and increasing family planning coverage. However, the first year after birth is given less emphasis regarding contraceptive utilization [6]. In Ethiopia, nearly half of all nonfirst pregnancies occur less than 24 months following the preceding birth [7].

Studies have revealed that the first year following delivery is so complex and different from other times in a woman's life cycle due to the additional burden to care for her infant and the series of emotional and physical changes [5-7].

The prevalence of contraceptive use among postpartum women varies from region to region in Ethiopia, as most women do not start taking contraceptives at the recommended time $[7,8]$. Even those who use PPFP rely on traditional, mainly lactational amenorrhea (LAM) that might pose the risk of unintended pregnancy. Therefore, initiating appropriate contraception in the postpartum period is important to avoid negative health outcomes [8].

Few studies conducted in Ethiopia indicated that PPFP uptake is low with the most common determinants affecting uptake being sociodemographic characteristics, antenatal care (ANC) attendance, resumption to sexual activities, postnatal care (PNC) attendance, the return of menses, and duration after delivery [3, 9-11]. These studies tried to measure magnitude and factors that are positively associated with PPFP uptake and, none of these studies so far have well-addressed barriers to PPFP uptake.

In general, studies in Ethiopia were conducted in towns and might not represent postpartum family planning uptake and possible associated factors in a rural community. Governmental attention, health facilities' concerns, and readiness, and health professional factors were not well investigated. Thus, the current study will address associated factors of postpartum family planning utilization in a rural part of Ethiopia.

\section{Methods}

\section{Study setting and design}

A cross-sectional quantitative study design was conducted in Western Ethiopia (Western Oromia and Benishangul Gumuz Regional State) public health facilities from September 1 to October 30, 2020. From Western Oromia, the zones included were East wollega, Horroguduru wollega, and west Wollega. Benishangu Gumuz Regional State is one of the 10 regional states in Ethiopia. It is adjacent to the Western part of Oromia regional state. Assosa is the capital city of this region and is located $670 \mathrm{~km}$ from the west of Addis Ababa. Assosa zone is included in this study. The study is conducted in five hospitals and ten health centers in western Oromia, and two hospitals and five health centers from Benishangu Gumuz Regional State.

\section{Study design}

A cross-sectional study design with a quantitative method was conducted.

\section{Source population}

The source population for this study was all postpartum mothers aged between 15 to 49 years who were living in the catchment population of the study facilities.

\section{Study population}

The study population was postpartum mothers who have given birth in the last 12 months of the study period and visiting the selected study hospitals and health centers for any maternal, neonatal, and child health services.

\section{Eligibility criteria Inclusion criteria}

Postpartum women who gave birth in the last 12 months. 
Postpartum mother who gave her consent to the study.

\section{Exclusion criteria}

Postpartum mothers who were severely sick and unable to talk were excluded from the study.

\section{Sample size determination}

The single population proportion formula was used to calculate the sample size with the following assumption. The proportion of postpartum women who utilized postpartum family planning which was $48.11 \%$ was taken [10]. The marginal error of $4 \%$, design effect 1.5 , and 95\% confidence level. After adding a 10\% non-response rate, the final sample size was 990 .

\section{Sampling techniques}

In this study, the East Wollega zone, Horroguduru Wollega, and West wollega zones were included from western Oromia while the Assosa zone was included from Benishangul Gumuz. All types of hospitals and districtlevel health centers that are currently providing postpartum family planning services were considered in the study. The total list of hospitals and health centers in the study zones was obtained from zonal health departments of the study zones. Then, the study hospitals and health centers were selected by simple random sampling. The weekly average client load of the target age group in the $\mathrm{MNCH}$ department of study health facilities was taken from registry books and the respective sample size for each selected health facility was allocated proportionally to their $\mathrm{MNCH}$ department client flow. Finally, an eligible postpartum woman who had been selected by systematic random sampling was interviewed at an entry point.

\section{Study variables}

\section{Dependent variable}

Postpartum family planning uptake.

\section{Independent variables}

socio-demographic characteristics, husband education and occupation, obstetric factors, family planning related factors, breast feeding, facility readiness, place of delivery, and COVID-19 pandemic restrictions.

\section{Data collection procedures}

Data were collected by 25 data collectors who know Afan Oromo and Amharic. The quantitative data were collected through interviewer-administered interviews using adopted questionnaires from reviewed literature on postpartum family planning [3, 10-25]. Inorder to minimize potential bias, the authors used precise tools and well trained female BSC nurses,who were not working in the same facility/study area, for data collection.

\section{Data processing and analysis}

The data were checked, entered, and cleaned using EPIINFO version 7.0 and then exported to Statistical Package for Social Sciences (SPSS) software package version 25 for analysis. Using the odds ratio (OR) with a 95\% limit of the confidence interval, the association of dependent and independent variables was identified, and their degree of association was computed. Potential confounding variables were controlled by using multiple logistic regression.

Descriptive statistics (like frequencies, percentages) were used to describe the study population in relation to dependent and independent variables. Results were presented in text, graph, charts, and tables.

\section{Data quality control}

The training was given for the data collectors and supervisors on the objective of the study, how to conduct interviews. The data collection was regularly monitored daily for completeness. Data collection was done in the local language. Moreover, the field teams were provided the necessary personal protective equipment during the training, pretest, and actual data collection. As a precaution for COVID-19, the study participants were also provided face masks during the interview process.

\section{Results}

Socio-demographic characteristics of participants

In this study, 989 postpartum women were participated making a response rate of $99.89 \%$. Six hundred thirty $(63.70 \%)$ and $359(36.30 \%)$ of participants were from Western Oromia and Beneshangul Gumuz Regional States respectively. Regarding the age group of participants, the result indicated that more than two-third, 649 $(65.62 \%)$ were those aged between 20 to 29 years. The majority, 599 (60.57\%), of the participants were from rural areas. Six hundred eight nine $(69.7 \%)$ of the participants were Oromo (69.67\%) followed by Amhara 151 (15.3\%)(Table 1).

\section{Reproductive characteristics of study participants}

In this study, the majority of study participants, $48.6 \%$, were para 2 and 3. Most of the participants, 817 (82.6\%), had ANC follow-up for the index pregnancy. From these, more than half, 459 (56.18\%) had at least four antenatal care visits. One hundred thirty-six (13.8\%) of study participants had a history of abortion. One hundred nine (11\%) had ever encountered unintended pregnancy and $63(6.40 \%)$ had a history of stillbirth. Three fourth, 744(75.2), of the study participants, had attended postnatal care. Among them, the majority 341(45.8\%) 
Table 1 Sociodemographic characteristics of study participants, Western Ethiopia, 2020

\begin{tabular}{|c|c|c|c|}
\hline \multicolumn{2}{|l|}{ Characteristics } & \multirow{2}{*}{$\begin{array}{l}\text { Frequency } \\
630\end{array}$} & \multirow{2}{*}{$\begin{array}{l}\text { Percentage } \\
63.7\end{array}$} \\
\hline Region & Oromia Regional State & & \\
\hline & Benshangul Gumuz Regional State & 359 & 36.3 \\
\hline \multirow[t]{5}{*}{ Age in years } & 15 to 19 & 36 & 3.6 \\
\hline & 20 to 24 & 235 & 23.7 \\
\hline & 25 to 29 & 414 & 41.8 \\
\hline & 30 to 34 & 209 & 21.1 \\
\hline & $>35$ & 95 & 9.6 \\
\hline \multirow[t]{2}{*}{ Residence } & Urban & 599 & 60.5 \\
\hline & Rural & 390 & 39.4 \\
\hline \multirow[t]{6}{*}{ Religion } & Protestant & 484 & 48.9 \\
\hline & Orthodox & 245 & 24.7 \\
\hline & Muslim & 234 & 23.6 \\
\hline & Adventist & 15 & 1.5 \\
\hline & Catholic & 6 & 0.6 \\
\hline & Wakefata & 5 & 0.5 \\
\hline \multirow[t]{3}{*}{ Marital status } & Married & 955 & 96.5 \\
\hline & Never married & 17 & 1.7 \\
\hline & Others & 17 & 1.7 \\
\hline \multirow[t]{4}{*}{ Ethnicity } & Oromo & 689 & 69.6 \\
\hline & Amhara & 151 & 15.2 \\
\hline & Berta & 95 & 9.6 \\
\hline & Others & 46 & 4.6 \\
\hline \multirow[t]{5}{*}{ Participant education } & Cannot read and write & 189 & 19.1 \\
\hline & Can read and write & 79 & 7.9 \\
\hline & Grade 1-8 & 255 & 25.7 \\
\hline & Grade 9-12 & 239 & 24.1 \\
\hline & College \& above & 227 & 22.9 \\
\hline \multirow[t]{6}{*}{ Participant occupation } & Farmer & 376 & 38.0 \\
\hline & Government employee & 309 & 31.2 \\
\hline & NGO employee & 26 & 2.6 \\
\hline & Merchant & 81 & 8.1 \\
\hline & Daily laborer & 143 & 14.4 \\
\hline & Student & 25 & 2.5 \\
\hline \multirow[t]{5}{*}{ Husband education } & Cannot read \& write & 110 & 2.5 \\
\hline & Read \& write & 80 & 11.1 \\
\hline & Grade 1 to 8 & 181 & 8.1 \\
\hline & Grade 9 to12 & 245 & 18.3 \\
\hline & College \& above & 344 & 24.7 \\
\hline \multirow[t]{6}{*}{ Husband occupation } & Farmer & 405 & 40.9 \\
\hline & Government employee & 309 & 31.2 \\
\hline & NGO employee & 26 & 2.6 \\
\hline & Merchant & 81 & 8.2 \\
\hline & Daily laborer & 143 & 14.4 \\
\hline & Student & 25 & 2.5 \\
\hline
\end{tabular}


Table 2 Maternal health service utilization among study participants, Western Ethiopia, 2020

\begin{tabular}{|c|c|c|}
\hline Variables & Frequency & Percent \\
\hline \multicolumn{3}{|l|}{ Parity } \\
\hline 1 & 277 & 28.0 \\
\hline 2 to 3 & 481 & 48.6 \\
\hline$\geq 4$ & 231 & 23.4 \\
\hline \multicolumn{3}{|l|}{ Unintended pregnancy } \\
\hline Yes & 109 & 11.0 \\
\hline No & 880 & 89.0 \\
\hline \multicolumn{3}{|l|}{ Abortion } \\
\hline Yes & 136 & 13.8 \\
\hline No & 853 & 86.20 \\
\hline \multicolumn{3}{|c|}{ ANC during the index pregnancy } \\
\hline Yes & 817 & 82.6 \\
\hline No & 172 & 17.4 \\
\hline \multicolumn{3}{|l|}{ Place of delivery } \\
\hline Health Facility & 808 & 81.7 \\
\hline Home & 181 & 18.3 \\
\hline \multicolumn{3}{|l|}{ Postnatal care } \\
\hline Yes & 744 & 75.2 \\
\hline No & 245 & 24.8 \\
\hline \multicolumn{3}{|c|}{ Time of Postnatal care visit } \\
\hline Within the first week & 280 & 37.6 \\
\hline 2 to 6 weeks & 341 & 45.8 \\
\hline$>6$ weeks & 123 & 16.5 \\
\hline \multicolumn{3}{|l|}{ Currently breastfeeding } \\
\hline Yes & 813 & 82.20 \\
\hline No & 176 & 17.80 \\
\hline
\end{tabular}

had attended postnatal care from 2 to 6 weeks. Two hundred eight (37.6\%) of participants attended postnatal care before the end of one week. More than $99 \%$ of these women attended postnatal care at health facilities. Eight hundred thirteen $(82.2 \%)$ of the women are reported to be currently breastfeeding (Table 2 ).

\section{Family planning methods used before the index pregnancy}

The participants were asked whether they had used any methods of the family before index pregnancy and it showed that the majority, $68.80 \%$, of postpartum mothers had used at least one method of family planning methods before the index pregnancy. Injectable forms and implants were the commonly used methods (Fig. 1).

\section{Post-partum family planning use among study participants}

Five hundred thirteen $(51.9 \%)$ of the study participants didn't discuss family planning with their husbands in the last year. However, more than half the participants 555 (56.1\%) had used family planning in the last year. The most common family planning methods used by participants were injectable form 287(51.7\%) followed by implants (24.5\%) (Fig. 2).

Among those who used the postpartum family planning method majority, 267(48.1\%) started the family planning method on the 45th day while those who started within a week and between six weeks to six months were $136(24.5 \%)$ and $91(16.4 \%)$ respectively. The main source of family planning method was health center 409(73.7\%) followed by hospital 94(16.9\%).

Four hundred one (72.3\%) of postpartum family planning users reported as they were using the method they

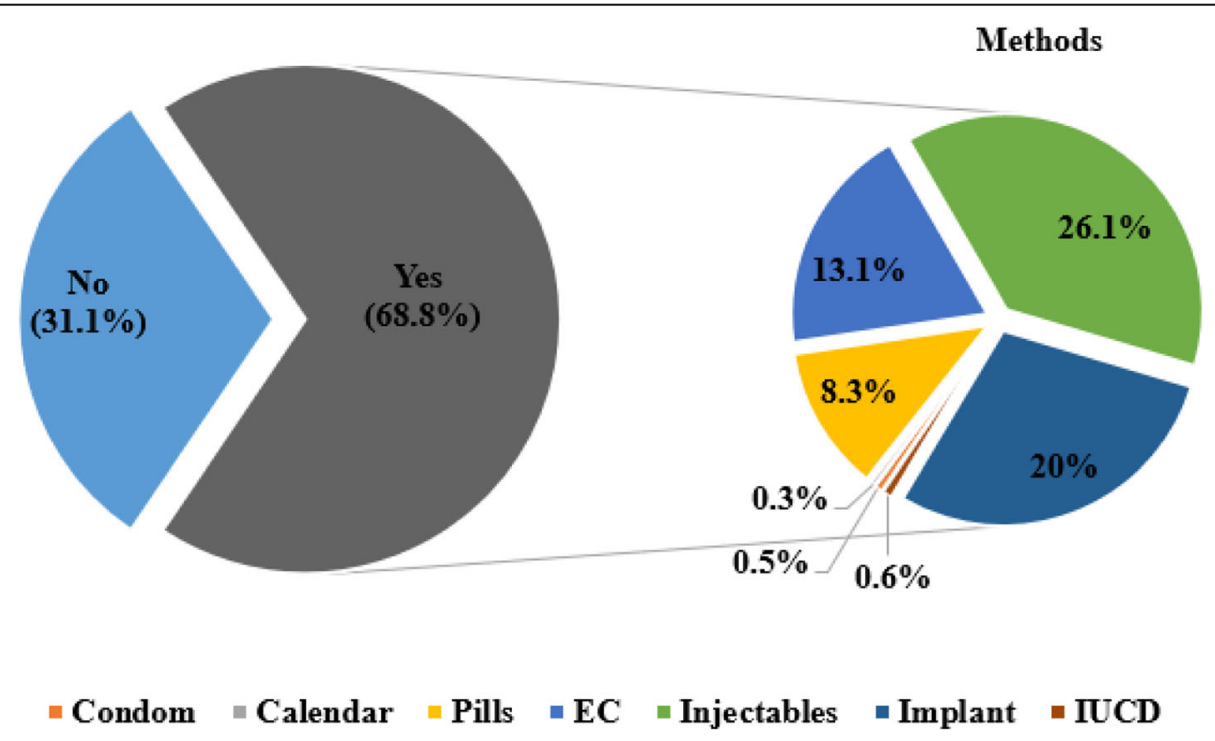

Fig. 1 Family planning utilization before the index pregnancy among study participants, Western Ethiopia, 2020 


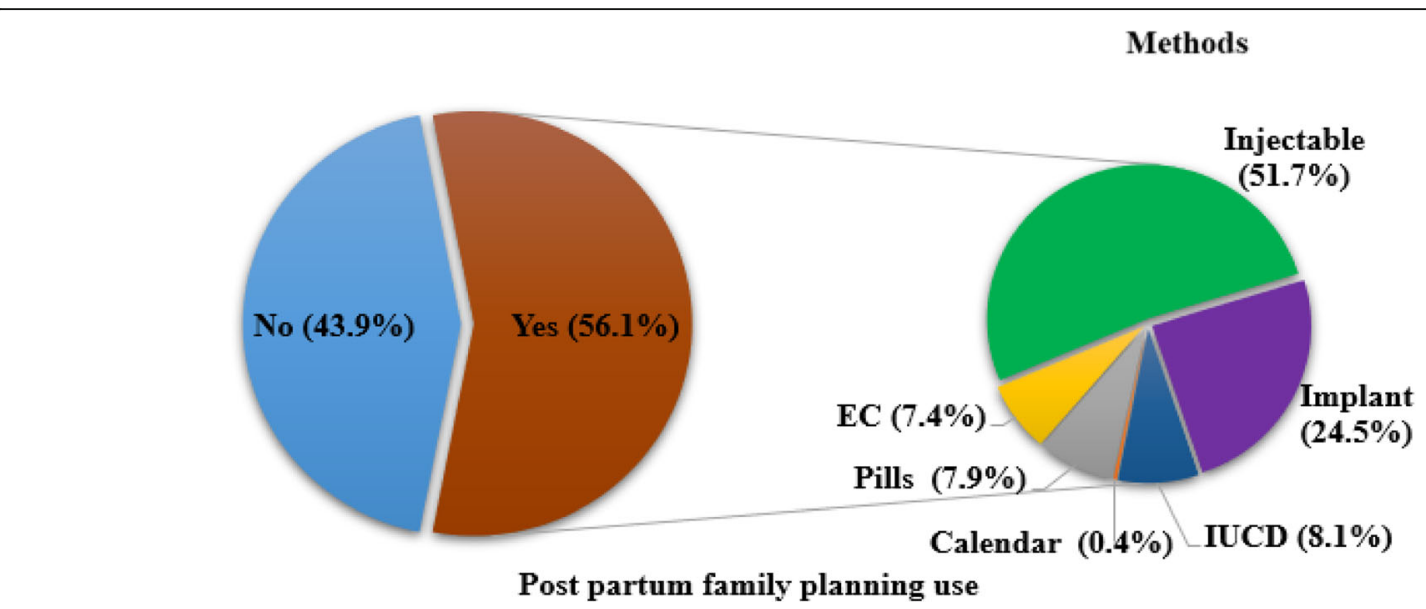

Fig. 2 Postpartum family planning utilization among study participants, Western Ethiopia, 2020

Table 3 PPFP uptake among study participants, Western Ethiopia, 2020

\begin{tabular}{|c|c|c|c|}
\hline Characteristics & & Frequency & Percentage \\
\hline \multirow[t]{2}{*}{ Received counseling on PPFP during ANC and delivery } & Yes & 753 & 76.1 \\
\hline & No & 236 & 23.9 \\
\hline \multirow[t]{2}{*}{ Previous history of PPFP uptake } & Yes & 342 & 48.2 \\
\hline & No & 368 & 51.8 \\
\hline \multirow[t]{2}{*}{ Currently using PPFP } & Yes & 555 & 56.1 \\
\hline & No & 434 & 43.9 \\
\hline \multirow[t]{5}{*}{ Time of initiation of PPFP uptake } & Within $24 \mathrm{~h}$ & 30 & 5.4 \\
\hline & Within a week & 136 & 24.5 \\
\hline & 2 to 6 weeks & 267 & 48.1 \\
\hline & 6 weeks to 6 months & 91 & 16.4 \\
\hline & After 6 months & 21 & 5.5 \\
\hline \multirow[t]{5}{*}{ Source of family planning } & Hospital & 94 & 16.9 \\
\hline & Health center & 409 & 73.7 \\
\hline & Health post & 33 & 5.9 \\
\hline & Private clinic & 16 & 2.9 \\
\hline & Pharmacy & 3 & 0.5 \\
\hline \multirow[t]{2}{*}{ Availability of the preferred method } & Yes & 424 & 76.4 \\
\hline & No & 131 & 23.6 \\
\hline \multirow[t]{4}{*}{ Reason for preference of the method } & Convenient to use & 172 & 40.6 \\
\hline & No need to remember & 33 & 7.8 \\
\hline & Advised by friends & 39 & 9.2 \\
\hline & Comfortable for health & 180 & 42.5 \\
\hline \multirow[t]{2}{*}{ Reason for using non-preferred methods } & Medical reason & 78 & 59.5 \\
\hline & Not available & 53 & 40.5 \\
\hline \multirow[t]{2}{*}{ Faced difficulty during COVID-19 restrictions } & Yes & 345 & 34.8 \\
\hline & No & 644 & 65.2 \\
\hline
\end{tabular}


preferred. The foremost mentioned reasons for preference of the methods were a convenience for use $172(40.6 \%)$ and being comfortable to health 180(42.5\%). On the other hand, the reasons mentioned by those participants who were using the non-preferred method were medical condition $78(59.5 \%)$ and lack of the preferred method in the health facility $58(40.5 \%)$.

Participants were asked if they did face difficulty accessing the family planning service during COVID-19 pandemics and one hundred fifty-seven (15.9\%) responded as they did. The most common stated difficulties we're unable to get transportation $100(63.7 \%)$ and absence of health extension workers 68(43.31\%) while fear of acquiring coronavirus accounts for 19(12.1\%) (Table 3).

Moreover, 434(43.9\%) of the study participants didn't use any form of family planning method. A quarter of them mentioned the reasons for not using were breastfeeding 114(26.3\%) and menses not yet resumed 109(25.1\%) [Fig. 3].

\section{Factors affecting uptake of postpartum family planning service utilization}

In bivariate analysis, utilization of postpartum family planning services was significantly associated with variables like great or equal to para two, history of using family planning before the index pregnancy, previous history of postpartum family planning utilization, counseling given during antenatal follow-up, and delivery on postpartum family planning utilization, place of delivery, a skilled birth attendant at birth, and ANC attendance for the index pregnancy. However, currently living with husband, history of abortion, history of unintended pregnancy, and COVID-19 restrictions have no positive association with the uptake of postpartum family planning services. After adjusting for confounding factors in the multivariate analysis, factors that significantly associated with utilization of postpartum family planning services were history of using family planning before the index pregnancy, previous history of postpartum family planning utilization, counseling during delivery on postpartum family planning utilization, place of delivery, a skilled birth attendant at birth and COVID-19 restrictions. The number of parties and ANC attendance for the index pregnancy were not significantly associated with the service utilization in this study.

Participants who had been counseled during antenatal care and delivery about postpartum family planning were 4.89 times more likely to use the service compared to their counterparts $[\mathrm{AOR}=4.89(2.31,10.37)]$. Postpartum mothers who gave birth at the health facility were more than 7,61 times likely to use the postpartum family planning service compared to those delivered at home $[\mathrm{AOR}=7.61(4.36,13.28)]$. It was also checked whether a skilled birth attendant is associated with the service utilization and the multivariable logistic regression result indicated that those mothers who were assisted by skilled birth attendants at birth were around 4.99 times more likely to uptake the service compare to those assisted by non-skilled attendants $[\mathrm{AOR}=4.99(2.88$, 8.64)]. Postpartum family planning utilization was also 2 times higher among mothers who had used family planning before the index pregnancy $[A O R=2.09(1.29$, 3.41)].

COVID-19 restrictions were checked whether it affected uptake of the service and the result indicated that those postpartum mothers who faced restrictions of COVID-19 were by $39.5 \%$ less likely to use postpartum

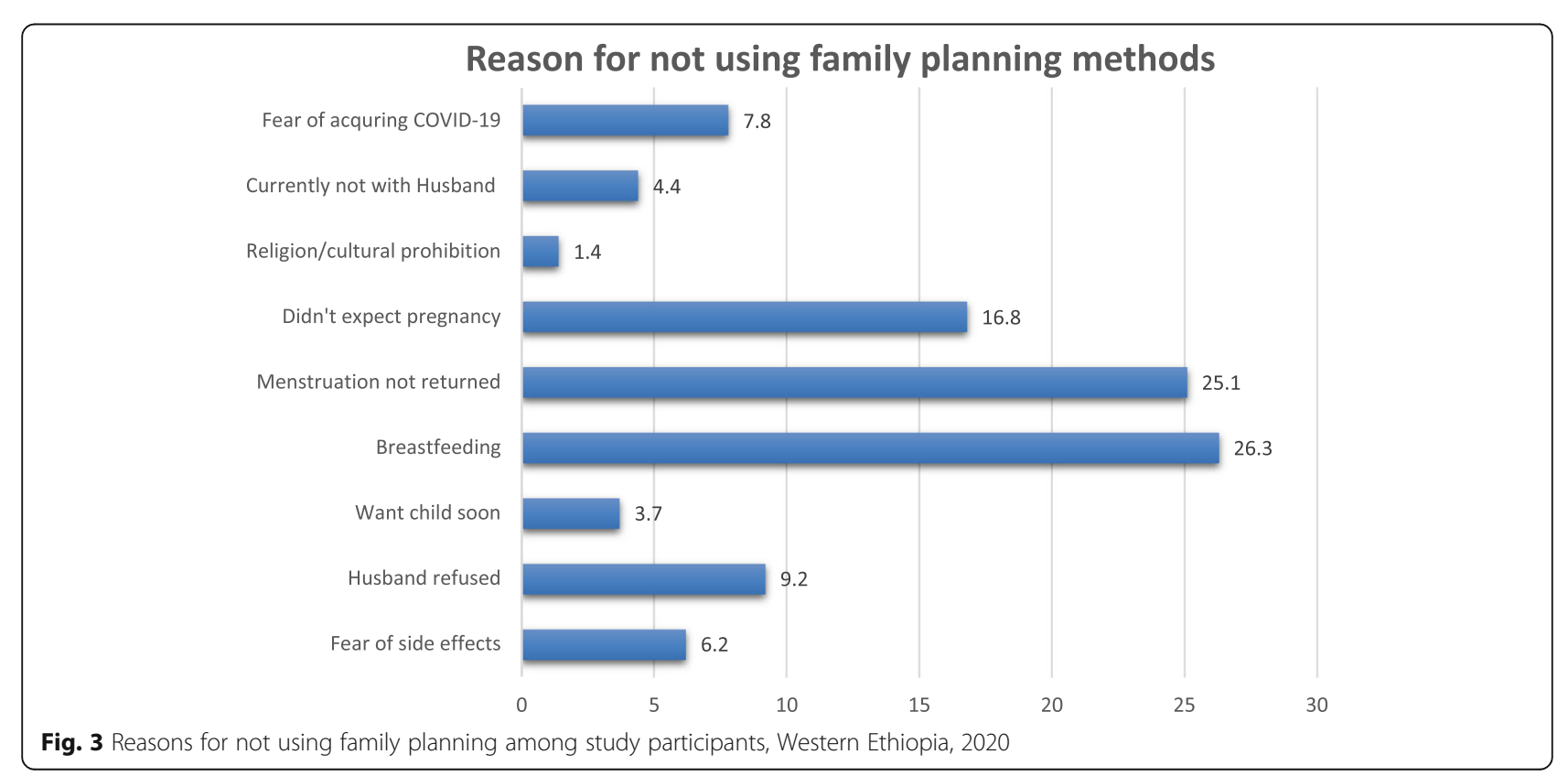


Table 4 Multivariable Logistic Regression of factors affecting PPFP uptake among study participants, Western Ethiopia, 2020

\begin{tabular}{|c|c|c|c|c|c|}
\hline \multirow[t]{2}{*}{ Variables } & \multicolumn{2}{|c|}{ PPFP utilization } & \multirow[t]{2}{*}{ COR at $95 \%$ C. I } & \multirow{2}{*}{$\begin{array}{l}\text { AOR at } 95 \% \mathrm{C} \text {. } \\
\text { I }\end{array}$} & \multirow[t]{2}{*}{$P$-value } \\
\hline & Yes & No & & & \\
\hline \multicolumn{6}{|l|}{ Parity } \\
\hline 1 & $219(79.1 \%)$ & $58(20.9 \%)$ & $0.24(0.17,0.34)$ & $1.21(0.80,1.82)$ & \multirow[t]{3}{*}{0.36} \\
\hline 2 to 3 & $231(48 \%)$ & $250(52 \%)$ & $0.22(0.15,0.33)$ & $1.18(0.71,1.73)$ & \\
\hline$\geq 4$ & $105(45.5 \%)$ & $126(54.5 \%)$ & 1 & & \\
\hline \multicolumn{6}{|c|}{ Family planning utilization before the index Pregnancy } \\
\hline Yes & $491(68.5 \%)$ & $226(31.5 \%)$ & $7.06(5.12,9.74)$ & \multirow[t]{2}{*}{$2.09(1.29,3.41)$} & \multirow[t]{2}{*}{$0.03^{*}$} \\
\hline No & $64(23.5 \%)$ & $208(76.5 \%)$ & 1 & & \\
\hline \multicolumn{6}{|c|}{ Previous history of PPFP utilization } \\
\hline Yes & $277(51.0 \%)$ & $266(49.0 \%)$ & $1.90(1.33,2.73)$ & \multirow[t]{2}{*}{$1.07(0.55,2.07)$} & \multirow[t]{2}{*}{0.89} \\
\hline No & $59(35.3 \%)$ & $108(64.7 \%)$ & 1 & & \\
\hline \multicolumn{6}{|c|}{ Counseling on PPFP during ANC \& delivery } \\
\hline Yes & $447(59.4 \%)$ & $306(40.6 \%)$ & $1.73(1.29,2.32)$ & \multirow[t]{2}{*}{$4.89(2.31,10.36)$} & \multirow[t]{2}{*}{$0.00^{*}$} \\
\hline No & $108(45.8 \%)$ & $128(54.2 \%)$ & 1 & & \\
\hline \multicolumn{6}{|l|}{ Place of delivery } \\
\hline Health facility & $525(65.0 \%)$ & $283(35.0 \%)$ & $9.34(6.15,14.18)$ & \multirow[t]{2}{*}{$7.61(4.35,13.28)$} & \multirow[t]{2}{*}{$0.00^{*}$} \\
\hline Home & $30(16.6 \%)$ & $151(83.4 \%)$ & 1 & & \\
\hline \multicolumn{6}{|c|}{ Skilled birth attendance } \\
\hline Yes & $450(53.5 \%)$ & $391(46.5 \%)$ & $2.12(1.45,3.10)$ & \multirow[t]{2}{*}{$4.99(2.87,8.63)$} & \multirow[t]{2}{*}{$0.00^{*}$} \\
\hline No & $105(70.9 \%)$ & $43(29.1 \%)$ & 1 & & \\
\hline \multicolumn{6}{|c|}{ Faced difficulty during COVID-19 restrictions } \\
\hline Yes & $185(53.6 \%)$ & $160(46.4 \%)$ & $1.17(0.9,1.52)$ & \multirow[t]{2}{*}{$0.59(0.39,0.9)$} & \multirow[t]{2}{*}{$0.01 *$} \\
\hline No & $370(57.5 \%)$ & $274(42.5 \%)$ & 1 & & \\
\hline \multicolumn{6}{|c|}{ ANC during the index pregnancy } \\
\hline Yes & $430(58.8 \%)$ & $301(41.2 \%)$ & $1.52(1.14,2.02)$ & \multirow[t]{2}{*}{$1.03(0.65,1.65)$} & \multirow[t]{2}{*}{0.89} \\
\hline No & $125(48.4 \%)$ & $133(51.6 \%)$ & 1 & & \\
\hline
\end{tabular}

*statistically significant

family planning services compared to those who did face restrictions $[\mathrm{AOR}=0.59(0.39,0.90)]$ (Table 4$)$.

\section{Discussion}

This study is aimed to assess barriers and determinants of postpartum family planning uptake among postpartum women in western Ethiopia. The study identified numerous factors that affect its uptake among postpartum women in western Ethiopia.

Nearly all of the study participants, (98.5\%), had heard of at least one method of family planning. This is similar to studies conducted in Hossana town, Southern Ethiopia (98.6\%) [12], and Aroressa (99.7\%) [13]. However, the finding of the current study is higher compared to the study conducted in Bahirdar town, Northern Ethiopia [11]. This discrepancy could have resulted from differences in the study setting and period.

In the current study, despite the high level of awareness, the uptake of postpartum family planning was $56.1 \%$. This finding is higher than studies conducted in Pakistan (24.6\%) [26], Nigeria (40.6\%) [14], Liberia(11.9\%) [15], Uganda (28\%) [16], and Aroressa district in Southern Ethiopia (31.7\%) [13]. However, postpartum family planning uptake in this study is lower than studies conducted in Kenya (78.4\%) [17], Debre Tabor town in Ethiopia (63\%) [18], and Hosanna town in Ethiopia (73.9\%) [12]. The low uptake in the current study might be explained by perceptions of low pregnancy risk due to breastfeeding and postpartum amenorrhea.

In this study, the most common type of postpartum family planning used by participants was injectable (51.7\%) followed by Implants (24.5\%]. This finding is similar to different studies conducted in Aroressa district [13], Hossana town [12], Debretabor town [18], and the Tigray region [34] in Ethiopia. This might be due to the similarity of the socio-cultural status of the community and user preferences. However, studies conducted in Pakistan [28], China [29], and Nigeria [21] showed condoms as the preferred method among study participants. 
The difference might be due to the study setting, awareness of the women about specific methods, and method mix strategies that different countries follow.

In this study, $72.3 \%$ of study participants were using the method they preferred. The most preferred method of contraceptive was injectable (64.39\%.). However, because of the lack of the preferred method and medical contraindications, only $72.3 \%$ of study participants were using the method they preferred. In Iran, the most preferred method of family planning was minipills (29.3\%) [19]. the study conducted in Turkey [35\%] [20] and Rwanda (52\%) [21], showed LARC methods as the most preferred method. The difference could be due to differences in the study setting and the strategies different countries are following.

In this study, $45.9 \%$ of the study participant did not start using any form of family planning methods. The major reasons mentioned were being breastfeeding (26.3\%) and failure of menses to resume 109(25.1\%). This could lead postpartum women to unintended pregnancies, abortions, and unplanned births [22]. Poor male engagement could also contribute to low utilization. Postpartum women experience amenorrhea for varying lengths of time, and their fertility can return before menses resume, even when breastfeeding [2]. Therefore, health professionals better deal with these misconceptions during counseling. Other studies in other countries identified different reasons. For instance, desire for more children and husband objection, and post-partum abstinence followed by fear of side effects of the methods and being breastfeeding were the dominant reasons in Turkey [20] and Liberia [15]. These differences might be explained by differences in the study setting, cultural differences, and health policies.

In the current study, participants who used family planning before the index pregnancy were twice more likely to use postpartum family planning than their counterparts. This is similar to the conducted in Addis Ababa where women who had no history of contraceptive use before their last birth were $88 \%$ less likely to use the family planning method during the postpartum period compared to those who had [23]. Therefore, promoting family planning utilization before pregnancy is essential to improve postpartum utilization.

Participants who received counseling on postpartum family planning during antenatal follow-up and delivery were five times more likely to utilize the services compared to those with not counseled. This is similar to the study conducted in Southern Ethiopia [24]. Therefore, strengthening counseling on postpartum family planning is important to promote its uptake.

This study showed that those participants who were assisted by skilled birth attendants at birth were 7 times more likely to utilize postpartum family planning compare to those assisted by non-skilled attendants. This is similar to the study conducted in Burundi and Rwanda where skilled birth attendance significantly affected the utilization of PPFP [16]. This could be because of the counseling health providers do during delivery.

The current study is conducted in the era of the COVID-19 pandemic where there are restrictions. The result indicated that those participants who faced difficulties during the COVID-19 pandemic were 39\% less likely to use postpartum family planning services compared to those who did not face it. This is in line with the projection that some 47 million women in 114 lowand middle-income countries are to be unable to use modern contraceptives if the average lockdown, or COVID-19-related disruption, continues for 6 months with major disruptions to services [25]. The authors recommended the health sector design an effective option to maintain postpartum family planning services during COVID-19 restrictions or related health crises.

In this study, it is revealed that there is no association between ANC attendance and uptake of postpartum family planning. This is consistent with another finding in which no difference in PPFP use was observed between women who received PPFP counseling only in ANC and women who did not receive counseling at all [24].

\section{Strengths and limitations of this study}

This study is the first of its kind invoving two regions, Oromia and Benshangul Gumuz regions, in western Ethiopia. The relatively large sample size and high response rate could make the findings generalisable to postpartum women in western Ethiopia. However, it was not without limitations. First, given the cross-sectional design of the study, it was not possible to establish cause-effect relationships of postpartum family planning uptake with independent variables. Second, partners (husbands) and health care provider perspectives were not addressed.

\section{Conclusion and recommendations}

Post-partum family planning utilization among study participants was low. Given the associated factors, it is recommended that health facilities should make postpartum family planning one of their top priorities and focus on these factors to improve its utilization.

\section{Abbreviations}

ANC: Antenatal care; AOR: adjusted odds ratio; COVID-19: corona virus disease 19; HSDP: Health Sector Development Plan; IUCD: Intrauterine Contraceptive Device; LAM: lactational amenorrhea; LMICS: low and middleincome countries; OR: odds ratio; PNC: postnatal care; PPFP: Postpartum Family Planning; WHO: World Health Organization 


\section{Acknowledgments}

We are grateful to Wollega University for the facilitation of the necessary research processes, including a support letter. Our gratitude and respect also go to Marie Stopes International Ethiopia for funding this research work.

\section{Authors' contributions}

TT was involved in Conceptualization, Data curation, Funding acquisition, Investigation, Methodology, Project administration, Supervision, Writing original draft, and Writing - review \& editing. TTB, MG, RO \& AS were involved in Conceptualization, Formal analysis, Investigation, Methodology, Resources, Software, Writing - original draft, and Writing - review \& editing All authors read and approved the final manuscript.

\section{Funding}

Marie Stopes International Ethiopia provided funding for this research.

\section{Availability of data and materials}

The data sets used and analyzed during the current study are available from the corresponding author on formal request.

\section{Declarations}

\section{Ethics approval and consent to participate}

Ethical clearance was obtained from the Research Ethics Committee of the Institute of Health Sciences, Wollega University before data collection began. Then, a support letter was written to the study zones to request the necessary support of the different districts and facilities in the zone. Each eligible study participant provided written consent. The study subjects were informed that the study would not involve any risks. Also, the objectives and benefits of the study were explained to them. To ensure privacy and confidentiality, the questionnaire did not collect identifying information. Moreover, interview was conducted in separate room.

The right of an individual to not participate in the study was respected. The filled questionnaire notes were taken, and recorded audio was kept confidential in a locked place.

The right of an individual not to participate in the study was also respected. The filled questionnaire, note taken and recorded audio was kept confidential in a locked place. Once agreed to participate, the participants were provided masks for the prevention of any possible contraction of COVID-19 during the interview.

\section{Consent for publication}

Not applicable.

\section{Competing interests}

The authors declare that they have no competing interests.

\section{Author details}

${ }^{1}$ Department of Obstetrics \& Gynecology, School of medicine, Institute of Health Sciences, Wollega University, Nekemte, Ethiopia. ${ }^{2}$ Department of Public Health, Institute of Health Sciences, Wollega University, Nekemte, Ethiopia. ${ }^{3}$ Department of Reproductive Health and Health Service Management, College of Health Sciences, Addis Ababa University, Addis Ababa, Ethiopia.

Received: 18 August 2021 Accepted: 3 January 2022

Published online: 12 January 2022

\section{References}

1. USAID. Accelerating Access to Postpartum Family Planning (PPFP) in Sub Saharan Africa and Asia. PPFP Country Programming Strategies Worksheet. 2010;(5):5. Available from: http://ec2-54-210-230-186.accessed on 22 March 2021.

2. Gaffield ME, Egan S, Temmerman M. It's about time: WHO and partners release programming strategies for postpartum family planning. Glob Health Sci Pract. 2014;2(1):4-9. https://doi.org/10.9745/ GHSP-D-13-00156.

3. Borda MR, Winfrey W, McKaig C. Return to sexual activity and modern family planning use in the extended postpartum period: an analysis of findings from seventeen countries. Afr J Reprod Health. 2010;14(4):72-9.
4. Blazer C. Postpartum family planning : current evidence on successful interventions. Open Access J Contracept. 2016:53-67.

5. Dev R, Kohler P, Feder M, Unger JA, Woods NF, Drake AL. A systematic review and meta-analysis of postpartum contraceptive use among women in low- and middle-income countries. Reprod Health. 2019;16(1):154. https:// doi.org/10.1186/s12978-019-0824-4

6. FDRE M. Federal Democratic Republic of Ethiopia Ministry of Health Health Sector Development Program IV 2010/11 - 2014/15. [cited 2020 July 10] . Available from: https://www.healthynewbornnetwork.org/hnn-content/ uploads/HSDPIV-Final-Draft-October-2010-2.pdf.

7. USAID and MCHIP. Family Planning Needs during the First Two Years Postpartum in Ethiopia. 2015. [cited 2020 July 10] . Available from: https://www.mchip.net/sites/default/files/Ethiopia\%202011\%20DHS\%2 OReanalysis\%20for\%20PPFP.pdf

8. Central Statistical Agency(CSA)[Ethiopia]. Ethiopia Demographic and Health Survey 2011. Addis Ababa, Ethiopia, and Calverton, Maryland, USA. 2012. [cited 2020 July 10]. Available from: https://dhsprogram.com/pubs/pdf/PR1 0/PR10.pdf

9. Rutstein SO. Effects of preceding birth intervals on neonatal, infant and under-five years mortality and nutritional status in developing countries: evidence from the demographic and health surveys. Int J Gynaecol Obstet. 2005;89(Suppl 1):S7-24. https://doi.org/10.1016/j. ijgo.2004.11.012 Epub 2005 Jan 26. PMID: 15820369.

10. Mehare T, Mekuriaw B, Belayneh Z, Sharew Y. Postpartum contraceptive use and its determinants in Ethiopia: a systematic review and Metaanalysis. Int J Reprod Med. 2020;2020:1-14. https://doi.org/10.1155/2020/ 5174656.

11. Demie TG, Demissew T, Huluka TK, Workineh D, Libanos HG. Postpartum Family Planning Utilization among Postpartum Women in Public Health Institutions of Debre Berhan Town, Ethiopia. J Women's Health Care. 2018; 07(426):2167-0420

12. Gejo NG, Anshebo AA, Dinsa LH. Postpartum modern contraceptive use and associated factors in Hossana town. PLoS One. 2019;14(5):1-10.

13. Dona A, Abera M, Alemu T, Hawaria D. Timely initiation of postpartum contraceptive utilization and associated factors among women of childbearing age in Aroressa District, southern Ethiopia: a community-based cross-sectional study. BMC Public Health. 2018;18(1): 1100. https://doi.org/10.1186/s12889-018-5981-9.

14. Adeyemi AB, ljadunola KT, Orji EO, Kuti O, Alabi MM. The unmet need for contraception among Nigerian women in the first year post-partum. Eur J Contracept Reprod Health Care. 2005;10(4):229-34. https://doi.org/10.1 080/13625180500279763 PMID: 16448949.

15. Kaydor V, Adeoye IA, Olowolafe TA, Adekunle AO. Barriers to acceptance of post-partum family planning among women in Montserrado County, Liberia. Med J. 2018:19-26.

16. Rutaremwa G, Kabagenyi A. Postpartum family planning utilization in Burundi and Rwanda: a analysis of population-based cross-sectional data. Pan Afr Med J. 2018;30:1-11. https://doi.org/10.11604/pamj.2018.3 0.303 .15105 .

17. Chege PM, Laktabai J, Owuor H. Predictors of post-partum family planning uptake in Webuye Hospital, western Kenya. Afr J Prim Health Care Fam Med. 2017;10:1-6

18. Taye EB, Mekonen DG, Debele TZ. Prevalence of postpartum modern family planning utilization and associated factors among postpartum mothers in Debre Tabor town, north West Ethiopia, 2018. BMC Res Notes. 2019;12(1):17. https://doi.org/10.1186/s13104-019-4464-0.

19. Rahmanpour H, Mousavinasab SN, Hosseini SN, Shoghli A. Preferred postpartum contraception methods and their practice among married women in Zanjan. Iran J Pak Med Assoc. 2010;60(9):714-8.

20. Yilmazel G, Balci E. Preferences and related factors for postpartum contraception in pregnant women. Iran J Reprod Med. 2013;11(10):801-6.

21. Kitessa AD, Rulisa S, Ntasumbumuyange D, Aimable M, Ghebre R. Immediate postpartum family planning preferences among couples in Rwanda. Rwanda Med J. 2019;76(4):1-7.

22. Apanga PA, Adam MA. Factors influencing the uptake of family planning services in the Talensi district. Ghana Pan Afr Med J. 2015;20:1-9. https://doi. org/10.11604/pamj.2015.20.10.5301.

23. Gebremedhin AY, Kebede Y, Gelagay AA, Habitu YA. Family planning use and its associated factors among women in the extended postpartum period in Addis Ababa. Ethiopia Contracept Reprod Med. 2018;3(1):1-8. https://doi.org/10.1186/s40834-017-0054-5. 
24. Zimmerman LA, Yi Y, Yihdego M, Abrha S, Shiferaw S, Seme A, et al. Effect of integrating maternal health services and family planning services on postpartum family planning behavior in Ethiopia: results from a longitudinal survey. BMC Public Health. 2019;19(1):1-9. https://doi.org/10.1186/s12889-01 9-7703-3.

25. UNFPA, Avenir Health, Johns Hopkins University and Victoria University. Impact of the COVID-19 Pandemic on Family Planning and Ending Genderbased Violence, Female Genital Mutilation and Child Marriage. Interim Tech Note. 2020. [cited 2020 July 10]. Available from: https://www.unfpa.org/ sites/default/files/resource-pdf/COVID-19_impact_brief_for_UNFPA_24_A pril_2020_1.pdf

26. Bibi S, Shoukat A, Maroof P, Mushraf S. Postpartum contraception utilization and its impact on interpregnancy interval among mothers accessing maternity services in the public sector hospital of Hyderabad Sindh. Pak J Med Sci. 2019;35(6):1482-7. https://doi.org/10.12669/pjms.35.6.914.

\section{Publisher's Note}

Springer Nature remains neutral with regard to jurisdictional claims in published maps and institutional affiliations.

Ready to submit your research? Choose BMC and benefit from:

- fast, convenient online submission

- thorough peer review by experienced researchers in your field

- rapid publication on acceptance

- support for research data, including large and complex data types

- gold Open Access which fosters wider collaboration and increased citations

- maximum visibility for your research: over $100 \mathrm{M}$ website views per year

At BMC, research is always in progress.

Learn more biomedcentral.com/submissions 